\title{
Profissionais fazendo matemática: avanços e limites nos cálculos com números decimais
}

\author{
Maria José Gomes Cavalvante e Rute Elisabete de Souza Rosa Borba²
}

Resumo: O estudo teve como objetivo investigar os conhecimentos sobre números decimais de estudantes da Educação de Jovens e Adultos (EJA) que exercem diferentes profissões. Participaram oito estudantes (pedreiros e marceneiros) que resolveram 12 questões, envolvendo os conceitos de área e de perímetro, inseridos nos contextos de construção civil, marcenaria e agricultura. Por meio de entrevistas clínicas piagetianas, observamos que a experiência dos pedreiros e marceneiros mostrou-se significativa, em relação à elaboração de estratégias e às operações com números decimais para a resolução dos problemas, em contextos que lhes eram familiares e não familiares. Entretanto, alguns erros foram identificados nos cálculos numéricos realizados por alguns participantes, envolvendo, principalmente, a multiplicação e a subtração. Evidencia-se, portanto, tanto, a necessidade da escola aproveitar no ensino na EJA de estratégias utilizadas pelos estudantes nas suas práticas profissionais, como a de considerar que há dificuldades a serem superadas pelos estudantes e contribuir neste processo.

Palavras-chave: EJA, prática profissional, números decimais, contextos diversificados, operações.

\section{Professionals doing mathematics: advances and limits in calculations with decimal numbers}

Abstract: The present study aimed to investigate adults' knowledge about decimal numbers. The participants were students in initial process of schooling with different professions. Eight students (bricklayers and carpenters) solved 12 situations that involved the concepts of area and perimeter, in contexts of civil construction, carpentry and agriculture. By use of Piagetian clinical interviews, it was observed that the bricklayers and carpenters experiences were

1 Doutoranda em educação da UFPE. Professora da UFRPE/UAG - mariajose.uag@ig.com.br 2 Professora da UFPE - Professora da Pós-Graduação em Educação Matemática e Tecnológica (Edumatec).resborba@gmail.com 
significant in relation to strategy elaboration and arithmetic operations with decimal numbers, whilst solving area and perimeter problems, both in familiar and unfamiliar situations. Thus, some errors were identified in some participants' numerical calculus, involving, mainly, multiplication and subtraction. There is, thus, evidence of the need to take advantage at schooling in initial adult education of strategies used by students in their professional practices, and to consider that there are difficulties to be overcome by students and contribute to this process.

Key words: Initial adult schooling, professional practice, decimal numbers, different contexts, operations.

\section{Introdução}

Ao longo de nossa experiência como educadoras, várias têm sido as nossas indagações sobre a ação de ensinar e de aprender, e, ainda, sobre as especificidades pertencentes à Educação de Jovens e Adultos (EJA), uma vez que nesta modalidade de ensino encontram-se indivíduos com pouco ou nenhuma escolarização, mas com ricas experiências dentro de práticas sociais.

Apesar de elevado número de jovens e adultos que se encontra em processo inicial de escolarização no Brasil, podemos considerar que ainda são relativamente poucas as pesquisas na Educação de Jovens e Adultos, em particular as que dizem respeito à Educação Matemática na EJA. Danyluk (2001) e Fonseca (2002) afirmam a necessidade de pesquisas e publicações neste campo, buscando conhecer a identidade sócio-cultural, o potencial cognitivo e afetivo, enfim, as especificidades do estudante da EJA.

Tal necessidade nos motivou a contribuir nesta linha de investigação, por isso, nesta pesquisa de Mestrado, objetivamos investigar os conhecimentos sobre números decimais de estudantes de Educação de Jovens e Adultos que exercem diferentes profissões. Para isso, identificamos as estratégias pessoais utilizadas pelos participantes na resolução de problemas envolvendo números decimais, analisamos os erros e acertos cometidos nos cálculos realizados, bem como observamos a possibilidade de aplicação dos conhecimentos da experiência profissional para outras situações-problema que envolviam diferentes contextos.

Investigar estes conhecimentos se faz importante no momento em que reconhecemos os estudantes da EJA enquanto grupo ou grupos que possuem características próprias, que não podem ser desconsideradas em sua educação. 
A especificidade da EJA não é apenas a sua característica etária, como muitos ainda pensam. Fonseca (2002, p.15) enfatiza que "o grande traço definidor da EJA é a caracterização sócio-cultural de seu público, no qual se deve entender o corte etário que se apresenta na expressão que a nomeia".

Assim, quando nos referimos à Educação de Jovens e Adultos, falamos de uma educação dirigida a um sujeito que está iniciando ou retornando sua vida escolar, que tem a marca da exclusão social e cultural, causada pelo não acesso à escola ou não possibilidade de continuidade dos estudos, que busca uma primeira ou nova oportunidade de inclusão.

Esta inclusão (ou re-inclusão) à escola está também diretamente relacionada ao lugar social que é atribuído ao estudante da EJA pela sociedade, pois este condiciona a concepção de educação, bem como as condições políticas e materiais da educação que lhe são oferecidas.

\section{Processos de ensino e aprendizagem dos números decimais}

É comum ouvir, por parte de professores, que já ensinaram determinados assuntos, mas que os estudantes de suas turmas não conseguem aprender, ou que já explicaram várias vezes o mesmo conteúdo, mas os estudantes continuam com as mesmas dificuldades, sem conseguir superá-las.

Em virtude de situações como estas que envolvem processos de ensino e de aprendizagem não bem-sucedidas, pesquisadores e professores têm se debruçado sobre esta temática, na busca de conhecer e entender melhor estes processos.

Especificamente em relação à aprendizagem do conceito de número decimal, alguns estudos e pesquisas têm sido desenvolvidos e têm apontado algumas das dificuldades de estudantes em relação a este campo numérico. Dentre estes estudos, destacamos o realizado por Brousseau (1983) sobre os obstáculos à aprendizagem dos números decimais.

Segundo Brousseau (1983), obstáculos se apresentam quando o educando tenta aplicar o conhecimento consolidado que já possui a uma nova situação, porém, para aquela situação este conhecimento se mostra inadequado. No caso dos números decimais, os estudantes podem revelar uma certa resistência em rejeitar seus conhecimentos sobre números naturais e tentam, assim, ajustá-los às situações-problema envolvendo números racionais. Pode-se atribuir esta tentativa de manter-se no campo dos números naturais ao fato que, durante os anos iniciais do Ensino Fundamental, o estudante trabalha com 
quantidades discretas e a passagem deste campo para o dos números racionais é feita sem que ele sinta necessidade, o que leva o estudante a discretizar o contínuo, ou seja, moldar um problema de situação do contínuo para uma situação discreta.

Os obstáculos não devem ser, no entanto, encarados pelo professor como algo negativo, como produtos de efetiva ignorância ou mesmo desinteresse do estudante, mas, sim, como indicativos do conhecimento atual do educando. Deve-se, portanto, buscar formas de conhecer as origens dos obstáculos e modos de superá-los.

Outras pesquisas mais recentes têm sido realizadas no campo dos números racionais e mais especificamente quanto a números decimais, em geral, motivadas pelo desejo de superação das dificuldades no processo de ensino-aprendizagem neste campo numérico. Dentre estas, destacamos o estudo realizado por Porto (1995) que investigou a resolução de problemas de comparação e conversão de números decimais; as pesquisas realizadas por Rodrigues (2003) sobre a evolução da construção das escritas numéricas e seu uso ao longo do Ensino Fundamental; e a investigação realizada por Cunha e Magina (2004) sobre medidas e números decimais. Estas pesquisas apontam para as concepções e conhecimentos que os estudantes já possuem sobre números racionais.

Porto (1995) teve como objetivo investigar a competência de estudantes da $5^{a}$ série do Ensino Fundamental com números decimais em problemas de comparação e conversão de medidas. Foram realizadas 12 horas de observação em sala de aula, envolvendo situações de ensino sobre números decimais e, posteriormente, sessões de resolução colaborativas de problemas com 11 duplas de estudantes, que envolviam situações de composição e transformação de quantidades volumétricas com uso de objetos físicos e situações de comparação e de conversão de medidas métricas e temporais, bem como de computação de cálculos com números sem referentes explícitos.

Segundo Porto (1995), os resultados apresentados na pesquisa apontam para alguns aspectos interessantes para o ensino dos decimais aplicados a situações de conversão de medidas, que são: o tempo destinado a cada conteúdo variou em função do que o professor acreditou como necessário à compreensão do conteúdo pelos estudantes, sendo a carga horária maior destinada à execução das quatro operações e suas regras, em prejuízo da resolução de problemas no campo das medidas, dificultando a compreensão 
dos estudantes; a resolução de problemas com medidas temporais foi caracterizada por uma imposição das razões dos sistemas de medidas sobre as do sistema de representação decimal; as partes (inteira e decimal) do número eram usadas indistintamente pelos estudantes, os quais desconsideravam que a unidade de medida deveria permanecer a mesma sob a partição do inteiro; e as tarefas envolvendo conversão de medidas métricas foram resolvidas com sucesso pela aplicação de regras de manipulação da vírgula com apoio de escalas mnemônicas, ensinadas na sala de aula.

Estes resultados apontam para aspectos do ensino de decimais que precisam ser evitados e outros que precisam ser valorizados, pois tanto o estudo das relações e propriedades de números naturais e racionais, quanto a realização de operações aritméticas nestes campos numéricos devem ser levados em consideração, de forma equilibrada, a partir de situações contextualizadas (dentro e fora da Matemática) e que façam sentido aos estudantes.

A pesquisa realizada por Rodrigues (2003) objetivava identificar como evolui a construção das escritas numéricas e seu uso ao longo do Ensino Fundamental, envolvendo os conceitos de sistema de numeração decimal, números naturais e números racionais, com a participação de 10 crianças de cinco a seis anos e 927 crianças e adolescentes do Ensino Fundamental. A pesquisa mostrou que as crianças possuem um conhecimento numérico amplo e diversificado, construído a partir do contato cotidiano com os números, e que os estudantes do Ensino Fundamental $\left(2^{\mathrm{a}}, 4^{\mathrm{a}}\right.$ e $6^{\mathrm{a}}$ séries) têm algumas dificuldades no campo dos números naturais, mas estas se intensificam ao lidarem com números racionais, mediante a tentativa de aplicação das regras do campo dos números naturais aos racionais.

É preciso, portanto, que na escola a ampliação do campo dos naturais para o dos racionais ocorra com clareza para os estudantes de quais aspectos se mantém - como as propriedades do Sistema de Numeração Decimal - e quais se alteram - como a representação de partes inteiras, de décimos, centésimos etc.

Outra pesquisa neste campo foi a realizada por Cunha e Magina (2004) no campo dos números racionais sobre medidas e o número decimal, na qual identificaram algumas concepções, de 36 estudantes da $2^{\mathrm{a}}$ a $5^{\mathrm{a}}$ série, sobre números decimais mobilizadas no ensino dentro de determinados contextos. O estudo revelou que, ao lidar com números decimais, os estudantes tentam moldar um problema de situação do contínuo para uma situação discreta e, 
assim, trabalhar com uma falsa unidade natural.

As autoras acima citadas concluíram que há falhas de conceituação dos números decimais durante a conversão das representações da linguagem natural escrita ou falada para decimal por parte dos estudantes e que uma das dificuldades de trabalhar com números decimais pode estar relacionada com a ausência de conexão possível do estudante estabelecer, entre a medida e o número decimal.

Diante destas constatações, vemos que existe a necessidade de buscar alternativas metodológicas, que oportunizem a superação destes obstáculos à aprendizagem do conceito de número decimal.

\section{A prática social e o aprendizado de números decimais}

A nosso ver, uma das alternativas para auxiliar a superação de dificuldades de aprendizagem dos decimais está em conhecer como os estudantes lidam com estes números em seu dia-a-dia, ou seja, identificar os conhecimentos que os estudantes elaboraram na sua prática social sobre números decimais, tomando por base pesquisas que comprovam que a prática social contribui para a elaboração de conceitos matemáticos.

Tem-se defendido que a cultura tem influencia no desenvolvimento cognitivo do homem. Dentre os que defenderam este pensamento destaca-se Vygotsky (1989) que apresentou as idéias de que, através das relações sociais travadas nos seu cotidiano, o homem é capaz de reconstruir significados e conceitos; que a reconstrução de significados e conceitos se dá desde a infância, através do contato da criança com sua família; e que ao longo da vida esses significados e conceitos vão ampliando-se através das novas relações que surgem na escola, no trabalho e em outros contextos sociais.

Em suas investigações, Vygotsky e sua equipe de colaboradores verificaram que a formação de conceitos ocorre por meio da observação, manipulação e vivência direta, em diferentes práticas sócio-culturais atividades diárias, que os sujeitos organizam para atender suas necessidades de existência, por exemplo, práticas de trabalho formal ou informal, práticas de lazer, como também pela instrução sistemática.

Apesar de origens diferentes, os conceitos elaborados a partir da experiência cotidiana e os conceitos elaborados na escola se complementam no momento em que os conceitos científicos são trabalhados na escola, abrindo 
caminho para revisão e a melhor compreensão dos conceitos que os estudantes trazem consigo. A relação entre conceitos elaborados na prática cotidiana e os desenvolvidos na escola, porém, não é tão facilmente estabelecida pelos estudantes. Encontramos na escola, principalmente na EJA, estudantes afirmando que nada sabem de Matemática, que "não possuem cabeça" para fazer as contas, quando em suas vidas realizam diversas atividades envolvendo diferentes conceitos matemáticos, demonstrando, assim, não terem consciência dos seus conhecimentos. Daí a necessidade da intervenção do professor, no sentido de resgatar este conhecimento, buscando estabelecer um diálogo igualitário entre o saber dito popular (saberes dos educandos e seus grupos de referência) e o saber científico (saberes escolares).

A formação de conceitos matemáticos e o uso da Matemática na vida diária e suas relações com a Matemática formal da escola tem sido documentados em diversas pesquisas, principalmente no campo da Psicologia Cognitiva (Abreu, 1988; Nunes Carraher, 1988; Schliemann, 1988; Magalhães, 1990; dentre vários outros), buscando verificar como as pessoas desenvolvem conceitos matemáticos através de experiências não formais em diferentes contextos sociais.

Em um de seus estudos, Schliemann (1988, p. 69-84) teve como objetivo analisar a contribuição da escolarização formal, em contraste com a contribuição da experiência de trabalho, na resolução de problemas relacionados à prática da marcenaria. Comparou-se o desempenho de 15 marceneiros, que aprenderam a profissão informalmente, e 28 aprendizes que freqüentavam um curso formal de marcenaria. A tarefa aplicada consistia em calcular a quantidade de madeira necessária à produção de cinco camas e calcular o preço das camas prontas. De forma geral, os profissionais obtiveram um melhor desempenho que os aprendizes. A autora constatou, a partir dos resultados obtidos, a importância da experiência diária na resolução de problemas, pois, em geral, os participantes buscavam uma resposta relacionada à sua experiência (profissional ou escolar), porém entre os marceneiros havia uma preocupação em encontrar uma resposta que fosse viável, o que não ocorreu com os aprendizes que geravam respostas inaceitáveis.

O que mais nos chamou atenção no relato deste estudo foi o fato que as estratégias de cálculo, embora diferentes entre os grupos, eram igualmente efetivas (com baixo índice de erros). Ressalta-se que os cálculos efetuados envolviam adição, subtração e multiplicação de números decimais. A autora 
coloca que isto é surpreendente (e nós concordamos), levando em consideração a variabilidade entre os grupos no que diz respeito aos anos de escolaridade, uma vez que no grupo de profissionais alguns deles eram não escolarizados.

Tratando também sobre a questão da contextualização e aprendizagem, em uma pesquisa realizada com 17 mestres-de-obras e 16 estudantes de $7^{a}$ série, Nunes Carraher (1988, p.101- 125) analisou os cálculos de proporção desenvolvidos pelos participantes do estudo, averiguando se o modelo de regra de três, ensinado na escola, e as estratégias construídas a partir da experiência profissional pelos mestres-de-obras implicavam na compreensão dos mesmos invariantes operacionais. Para o estudo foram utilizadas quatro plantas baixas de interiores, contendo a indicação de algumas dimensões e os participantes deveriam calcular o comprimento das paredes. A pesquisadora analisou os resultados, levantando o percentual de acertos, e observou que os mestres-deobras tiveram melhor desempenho que os estudantes nas escalas que lhes eram familiares e desempenho compatível aos estudantes nas outras.

As pesquisas apresentadas nos confirmam que é possível a construção de conhecimentos matemáticos no exercício de algumas profissões e que tais profissionais desenvolvem estratégias de cálculo para resolver situaçõesproblema que envolvem o seu contexto de trabalho. Porém, é comum a afirmação que esses conhecimentos são específicos e que só são aplicáveis ao seu contexto de origem.

Questionando tal afirmação, buscamos estudos que investigassem sobre a possibilidade de transferência de estratégias de cálculo de um contexto para outro. Encontramos o estudo muito interessante realizado por Magalhães (1990), que pesquisou sobre o conhecimento matemático acerca de proporção de 60 estudantes da classe de alfabetização e da $1^{\text {a }}$ série da Educação de Jovens e Adultos de escolas da cidade de Recife, que exerciam a profissão de cozinheira, visando esclarecer quais as suas estratégias usadas para resolver problemas e, ainda, analisou a possibilidade de transferência nos procedimentos e estratégias usadas em situação conhecida para outras situações consideradas não familiares. A autora concluiu que as participantes não só resolveram problemas de contexto familiar envolvendo o conceito de proporção, mas também foram capazes de transferir seus conhecimentos para resolver problemas em contextos que não lhes eram familiares.

Apesar de evidenciarem capacidade de transferência de seus conhecimentos, a relação entre conhecimentos desenvolvidos fora da escola e 
os conteúdos matemáticos escolares trabalhados nem sempre é reconhecido pelos estudantes da EJA. Magalhães (1990, p. 56) afirma que "na percepção dos sujeitos, conhecimento informal parece distante do aprendido na escola. Eles não conseguem relacionar e identificar os conhecimentos da aprendizagem formal com o aprendido no dia-a-dia", ou seja, as estudantes cozinheiras não tinham consciência do seu saber, achavam que nada sabiam de Matemática. É, especialmente, nestas situações que deve entrar em cena o educador, assumindo um papel de mediador propondo um caminho que leve o estudante a tomar consciência de sua forma de matematizar e propiciando uma forma de ampliação deste conhecimento, ao oportunizar sua aplicação a problemas de contextos diferentes.

Outro estudo sobre números decimais foi desenvolvido por Silva (2006), levantando saberes de adultos e comparando-os aos de crianças. Foram investigados conhecimentos de decimais de 32 adultos e 32 crianças que frequentavam uma escola da Rede Municipal de Ensino de Recife. Metade dos adultos e metade das crianças não haviam ainda recebido instrução formal em números decimais. Todos os participantes resolverem 16 problemas, elaborados com base na Teoria dos Campos Conceituais, ou seja, que variavam em significados de decimais envolvidos (parte fracionária ou divisão de um todo), em representações simbólicas a serem utilizadas (resolução oral ou por escrito), em propriedades associadas ao número decimal (comparação e conversão) e em contextos nos quais os problemas estavam inseridos (valores monetários discretos e valores métricos contínuos).

Esta pesquisa revelou que os adultos tiveram um melhor desempenho do que as crianças, mesmo quando eles não tinham nenhuma escolaridade em números decimais, pois se mostraram capazes de resolver problemas envolvendo este campo numérico em diversas situações, utilizando os conhecimentos das suas práxis. A amplitude do conhecimento dos adultos evidenciou-se nos diferentes significados, representações simbólicas, propriedades e contextos. Esta pesquisa vem ratificar que o conhecimento construído na prática social, na trajetória de vida dos jovens e adultos é significativo, útil e sólido e, principalmente, que há especificidades nos saberes dos estudantes da EJA e há necessidade de reconhecimento destas pela escola.

Este conjunto de estudos evidencia a construção de conhecimentos matemáticos por meio do exercício profissional e o presente estudo visa contribuir para reforçar estas evidências, observando conhecimentos de 
números decimais que são desenvolvidos por marceneiros e pedreiros e a possibilidade de transferência de conhecimentos de contextos familiares para contextos pouco ou não familiares.

\section{Método da presente pesquisa}

Colaboraram na realização do presente estudo oito profissionais (pedreiros e marceneiros), estudantes da Educação de Jovens e Adultos (EJA) dos Módulos I e II, de três escolas da cidade do Recife/PE: uma da rede estadual e outras duas que funcionavam em canteiros de obras. A seleção dos Módulos I e II se deu pelo nosso interesse em pesquisar estudantes que não tivessem recebido ainda instrução formal acerca de números decimais.

Os participantes foram distribuídos em dois grupos: Grupo dos pedreiros, formado por quatro participantes com experiência profissional mínima de quatro anos; e o Grupo dos marceneiros, formado por quatro participantes também com experiência profissional mínima de quatro anos.

Foi realizada com os participantes uma entrevista na qual resolviam 12 problemas envolvendo números decimais. As entrevistas foram realizadas individualmente, por meio do método clínico piagetiano, pois focamos as estratégias de cálculo utilizadas pelo participante para chegar à solução do problema proposto.

Estas situações foram contextualizadas, ou seja, relacionadas às atividades profissionais dos participantes, sendo: quatro delas de contexto de construção civil (revestimento de um piso, construção de muro, cobertura de laje de uma casa e construção de uma cisterna); quatro de contexto de marcenaria (revestimento de um quadro de fórmica, colocação de rodapé, colocação de uma moldura e revestimento de um guarda-roupa); e, ainda, quatro problemas de contexto de agricultura (plantação de milho num terreno, confecção de cerca de uma roça, limpeza de um terreno e feitio de um cercado), não familiares aos dois grupos de estudantes profissionais.

Nestes problemas era solicitado o cálculo de área ou perímetro, já que estes conceitos estão relacionados diretamente às profissões selecionadas, porém nossa atenção estava mais voltada para verificar as estratégias de cálculo utilizadas pelos estudantes em relação aos números decimais e a aplicação das estratégias em situações envolvendo contextos não familiares aos participantes.

Todas as situações foram apresentadas por escrito e lidas pela pesquisadora para os participantes, tantas vezes quanto necessárias. Os

$$
\text { Zetetiké - FE/Unicamp - v. 22, n. } 42 \text { - jul/dez-2014 }
$$


profissionais estudantes puderam escolher a maneira como iriam resolver as situações colocadas: verbalizando suas estratégias e/ou registrando em papel.

\section{Apresentação e discussão dos resultados da pesquisa}

Em relação aos resultados obtidos, apresentaremos, primeiramente, alguns dados gerais e depois focaremos os cálculos com números decimais efetuados pelos participantes.

$\mathrm{Na}$ Tabela 1 apresentamos os percentuais de acertos gerais dos dois grupos de participantes (pedreiros e marceneiros) nas 12 situações-problema propostas. Nesta tabela, diferenciamos dois tipos de cálculo envolvidos: numérico e relacional, terminologia sugerida por Vergnaud (1986). Caracterizamos como, cálculo relacional a escolha de estratégias para resolução das situações, ou seja, seleção de estratégias e operações a serem realizadas. O cálculo numérico refere-se à realização de contas, aplicação de procedimentos e algoritmos propriamente ditos.

Tabela 1- Percentual de acertos no cálculo relacional (CR) e no cálculo numérico (CN) por grupo de profissionais nas doze situações-problema

\begin{tabular}{c|c|c|c}
\hline GRUPOS & & CR & CN \\
& & $(\%)$ & $(\%)$ \\
\hline PEDREIROS & & 93,7 & 81,2 \\
\hline MARCENEIROS & & 89,5 & 87,5 \\
\hline
\end{tabular}

Podemos observar que os percentuais de acerto dos dois grupos de profissionais tanto no cálculo relacional como no cálculo numérico, foram altos (acima de 80\%), apenas com pequenas variações, o que nos aponta que os participantes demonstraram compreensão do conceito de área e perímetro e bom domínio das operações com números decimais necessárias à resolução dos problemas envolvendo estes conceitos.

Estes percentuais evidenciam a influência da prática profissional destes estudantes nos resultados obtidos, levando em consideração que o exercício das profissões de pedreiro e marceneiro envolve diretamente algumas atividades nas quais há necessidade do cálculo da área e do perímetro, bem como de 
operações com números decimais (relacionadas às medidas) e que os participantes não haviam tido experiência formal na escola com estes conceitos, pois se encontravam nos anos iniciais das suas escolarizações.

Podemos verificar, ainda, que os grupos obtiveram um melhor desempenho no cálculo relacional do que no cálculo numérico, indicando que a dificuldade dos grupos foi menor na elaboração de estratégias do que na operacionalização para a resolução dos problemas.

Nos Gráficos 1 e 2, comparamos o desempenho dos pedreiros e marceneiros, respectivamente, nos problemas envolvendo área e perímetro nos três contextos.

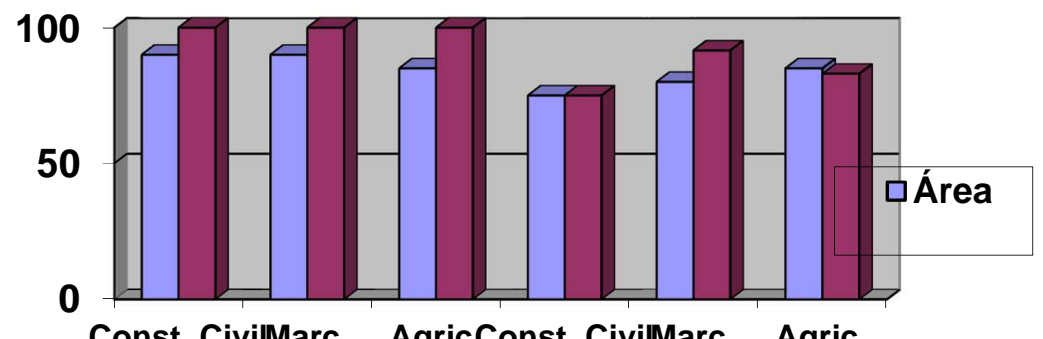

Const. CivilMarc. Agric.Const. CivilMarc. Agric.

$$
\text { Cálculo Relacional Cálculo Numérico }
$$

Gráfico 1 - Percentual de acertos no aálculo relacional e cálculo numérico do grupo dos pedreiros 


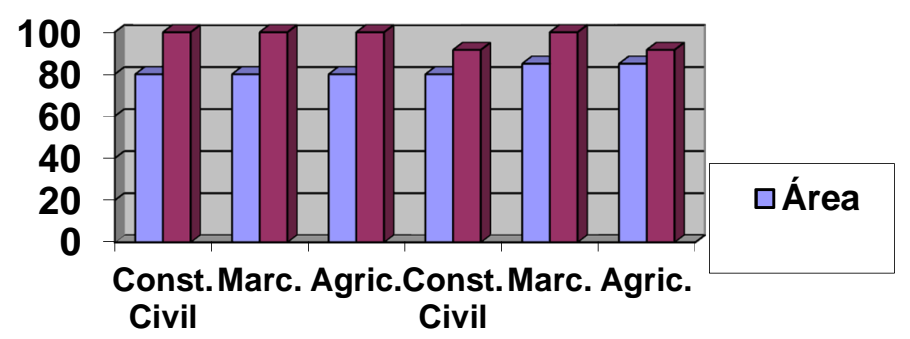

Cálculo Relacional Cálculo Numérico

Gráfico 2 - Percentual de acertos no cálculo relacional e cálculo numérico do Grupo dos marceneiros

Observamos que houve um melhor desempenho dos grupos nos problemas envolvendo o conceito de perímetro, pois se verifica que em todos os contextos houve $100 \%$ de acertos no cálculo relacional. O desempenho dos grupos nos problemas envolvendo o conceito de área foi também muito bom, visto que foram alcançados percentuais iguais ou maiores a $80 \%$.

Em relação ao cálculo numérico, os grupos alcançaram percentuais de acertos aproximados nos problemas de área e perímetro, demonstrando que possuíam um bom domínio na realização de operações envolvendo números decimais. Queremos salientar que, para resolver os problemas, os participantes tinham de fazer (no mínimo) duas operações, que podiam ser a multiplicação, adição e/ou subtração.

Vale salientar que em algumas situações os profissionais apresentaram dificuldades de natureza relacional e numérica que não podem ser desconsideradas, ao contrário, é preciso que se busque entendê-las para implementar intervenções pedagógicas apropriadas.

O que nos chama a atenção nestes resultados é o fato que os participantes 
alcançaram bons desempenhos não só nos problemas em que o contexto lhes era familiar, como era previsto, mas alcançaram aproximadamente os mesmos percentuais também nos problemas nos quais o contexto não era familiar, evidenciando que a compreensão dos conceitos de perímetro e área oportunizou aos participantes a transferência do conhecimento de uma situação familiar para outra não familiar.

Para a resolução dos problemas se fez necessária a realização de várias operações: multiplicação, adição e subtração com números decimais, que foram operacionalizadas de diversas maneiras pelos participantes. Abaixo apresentaremos uma sequência de problemas realizada por um participante pedreiro envolvendo a transferência de estratégia, bem como alguns erros apresentados por um participante marceneiro ao realizar o cálculo de operações como a multiplicação e a subtração.

É importante salientarmos que os participantes eram estudantes da EJA que estavam no início da sua escolaridade, e que não tinham trabalhando formalmente o conceito de números decimais.

\section{Aplicação do conhecimento sobre números decimais em diferentes contextos}

Através da análise das estratégias elaboradas para resolução dos problemas, observamos que houve a aplicação do conhecimento de um contexto familiar para os contextos pouco ou não familiares, pois a mesma estratégia realizada no primeiro problema era, em geral, transferida para a resolução dos outros problemas, que tinham os mesmos significados, os mesmos invariantes, as mesmas representações, porém os contextos eram diferentes. Por isso, durante a realização das entrevistas foram comuns afirmações dos estudantes, como:

"Quase o mesmo problema da primeira pergunta. É, é. Só muda que aqui é que vou trabalhar como pedreiro".

"Vou ter de fazer a mesma conta. É, a mesma conta que estava fazendo na cerâmica".

A sequência de resolução de três problemas (problemas dos contextos de construção civil, marcenaria e agricultura, respectivamente), que apresentamos em seguida, foi realizada por um participante pedreiro, que cursava o Módulo I da EJA, e evidencia a aplicação do conhecimento construído na práxis 
profissional em problemas que são relacionados e não relacionados a esta prática.

Os problemas envolvem o conceito de perímetro e para as resoluções requerem os seguintes conhecimentos subjacentes: a compreensão do enunciado; a leitura da figura apresentada; a leitura do retângulo; o domínio de sistema métrico; a identificação das medidas lineares para o cálculo do perímetro; a mobilização da fórmula do perímetro; a realização da operação com números decimais (adição e subtração); dentre outros.

Os problemas foram apresentados e para resolvê-los o estudante iniciou a resolução do problema fazendo uma adição e a efetuou corretamente, por meio do algoritmo convencional.

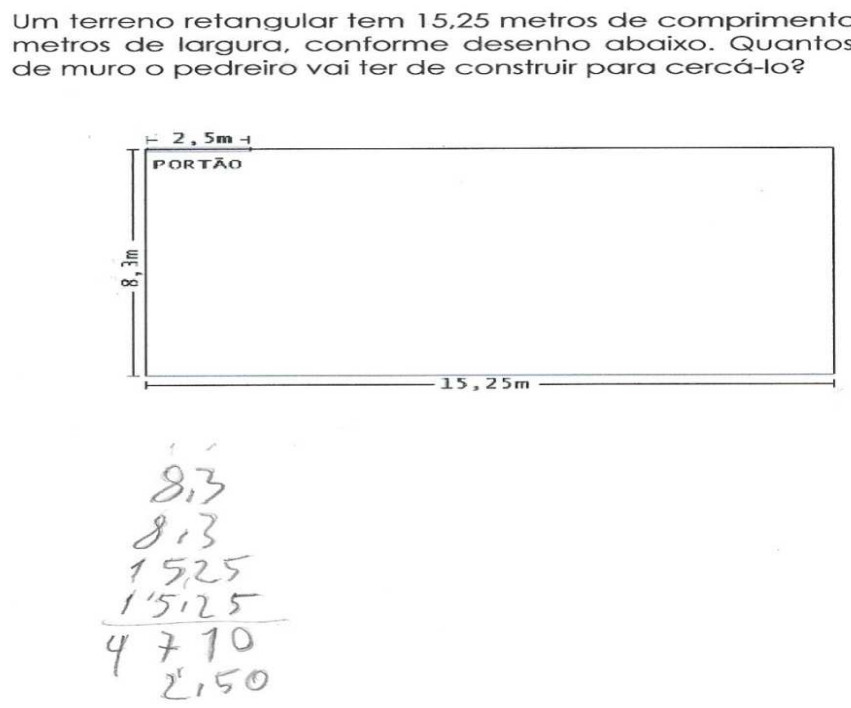

Estudante: Vou somar. É melhor somar?

Pesquisadora: Você que sabe.

O estudante armou a conta.

E: Oito virgula três e agora esse (referindo-se ao oito vírgula três da outra lateral). Esse 
de cima (referindo-se ao quinze vírgula vinte e cinco do comprimento) e agora de novo. Agora vou dar uma somada, né (sic)? Dez... cinco, dez.Quatro, sete, nove com dois onze, a um. Nove e oito dezessete, dezessete com cinco, vinte e dois com cinco vinte sete. Três, quatro. Quatro. Aqui deu quarenta e sete metros e um vírgula zero.

P: Quarenta e sete metros e... quanto?

E: Dez. Dez né (sic)? Quarenta e sete e dez... quarenta e sete metros e dez centímetros. Em seguida, o estudante pensou um pouco e disse: "vai tirar dois metros e cinquenta, porque é o lugar do portão". Pensou mais uma vez e disse que ia fažer o cálculo "de cabeça”.

E: Se fosse quarenta e sete menos dois e cinquenta ficava quarenta e quatro e cinquenta. O estudante repensou a resposta e fez o cálculo oral, novamente.

Estudante: Perai (sic) viu! Quarenta e cinquenta, no caso quarenta e quatro e sessenta, mais ou menos.

Pesquisadora: Como chegou você neste resultado?

E: Eu pensei por causa do portão lá, né (sic)? Quarenta e sete menos dois e cinquenta ai fica quarenta e quatro e cinquenta, mais os dez fica quarenta e quatro e sessenta.

P: Então quantos metros de muro o pedreiro vai construir?

E: Quarenta e quatro metros e sessenta centimetros.

Resumidamente, a estratégia do estudante foi uma adição com os quatro lados do retângulo, demonstrando compreender que o retângulo tem os lados opostos congruentes e que o perímetro se refere ao contorno (medida linear) de uma região, e uma subtração, para o cálculo da diferença entre o perímetro do terreno e a medida do portão. Esta diferença é a medida do muro a ser construído.

$\mathrm{Na}$ resolução do problema o estudante iniciou realizando uma adição, 
utilizando-se do algoritmo convencional, corretamente, demonstrando ter conhecimento das regras de operação deste algoritmo com números decimais. Para resolver a subtração, no entanto, o participante optou pelo não uso do algoritmo convencional e elaborou uma estratégia não convencional, utilizando-se do cálculo oral. Ele iniciou a estratégia subtraindo, quarenta e sete metros menos dois metros e cinquenta centímetros $(47 \mathrm{~m}-2,50 \mathrm{~m})$, chegando à diferença de 44 metros e 50 centímetros. Em seguida, somou os 10 centímetros, que haviam sido deixados dos 47,10, aos 44 metros e 50 centímetros $(44,50+0,10)$ e obteve o resultado de 44 metros e 60 centímetros de muro a ser construído.

O que percebemos de interessante na estratégia do participante, é que diferindo do algoritmo convencional que é aprendido da escola, que leva o estudante a conceber a subtração e adição como operações distintas, a operação de adição aqui foi utilizada conjuntamente à subtração, mostrando que estas operações podem ser complementares.

Após a resolução dos problemas familiares, foram propostos ao estudante os problemas de contextos pouco ou não familiares, primeiro os problemas do contexto de marcenaria e depois os de agricultura. 


\begin{abstract}
Num salão de festa que tem $17.25 \mathrm{~m}$ de comprimento por $10.3 \mathrm{~m}$ de largura, conforme o desenho abaixo, será colocado rodapé de madeira. Quantos metros de madeira serão usados no rodapé?
\end{abstract}
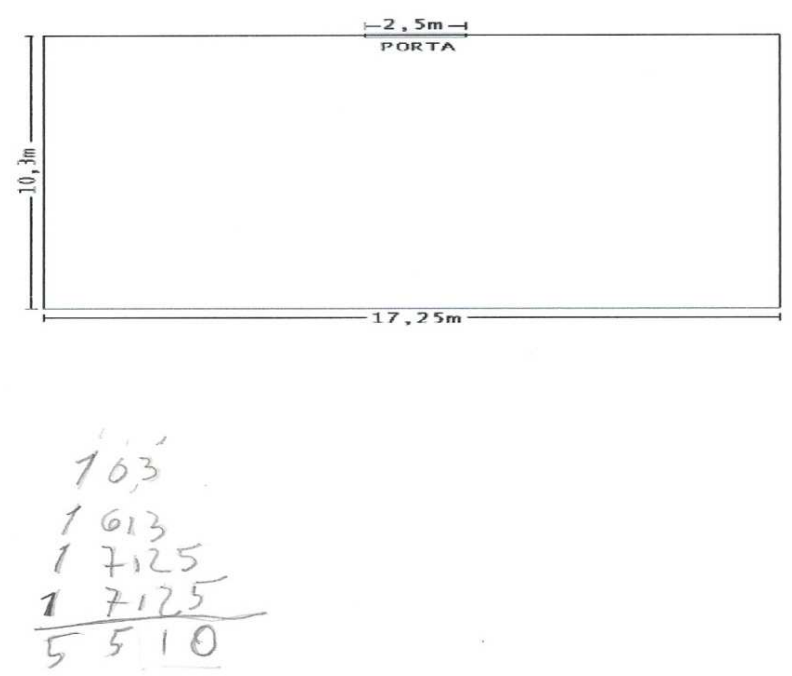

O estudante armou a conta: $10,3+10,3+17,25+17,25$.

Estudante: Encerrou um, dois, três, quatro (conferindo as parcelas da conta). Agora, somo, né (sic)? Cinco e cinco, dez. Dę a um. Quatro com três, sete, nove, dois, onže. Oito com sete, quinž, a um. Dois, três, quatro, cinco. Cinco. Pronto. Cinquenta e cinco metros e dez centímetros. Isso ai é o quê? Sim...

Pesquisadora: Você vai fažer o quê? Me explica.

E: Cinquenta e cinco metros e dez centímetros agora tem o menos de dois metros e cinquenta.

P. Sim.

E: Ai, no caso, fica cinquenta e dois metros e sessenta, no caso. 


\section{P: Me explica como é que dá cinquenta e dois metros e sessenta. \\ E: É que no caso deu cinquenta e cinco e dez menos dois cinquenta ... na minha cabeça... fica cinquenta e dois metros e sessenta, mais ou menos. Foi assim... cinquenta e cinco metros tirei dois metros e cinquenta, dá cinquenta e dois metros e cinquenta mais dez, cinquenta e dois e sessenta.}

P: Então, quantos metros de madeira serão usados no rodapé?

E: Cinquenta e dois metros e sessenta centímetros.

Podemos observar, claramente, que o participante utilizou as mesmas estratégias que haviam sido empregadas na resolução da situação-problema do contexto de construção civil (anteriormente apresentada) para resolver esta situação-problema do contexto de marcenaria.

$\mathrm{Na}$ resolução da situação de contexto de marcenaria, como na situação de contexto de construção civil, o participante iniciou realizando uma adição, utilizando-se do algoritmo convencional e, em seguida, na realização da subtração, empregou a mesma estratégia não convencional, utilizando-se também do cálculo oral. Ele iniciou a estratégia, subtraindo cinquenta e cinco metros menos dois metros e cinquenta centímetros $(55 \mathrm{~m}-2,50 \mathrm{~m})$, chegando à diferença de cinquenta e dois metros e cinquenta centímetros. Em seguida somou os dez centímetros aos cinquenta centímetros $(10 \mathrm{~cm}+50 \mathrm{~cm})$ e obteve o resultado de cinquenta metros e sessenta centímetros de madeira a serem utilizados no rodapé.

Achamos importante enfatizar que o participante que realizou esta seqüência era pedreiro e por isso a primeira situação apresentada (a construção de um muro) era de contexto familiar a ele. A segunda situação (a colocação de rodapé), porém, era de contexto não familiar ou menos familiar ao participante, porque consideramos que ela não está relacionada à prática profissional do pedreiro e, sim, do marceneiro. O contexto menos familiar, no entanto, não foi empecilho para que o participante resolvesse a situação, como poderíamos supor.

O que percebemos, comparando as estratégias empregadas na resolução das duas situações, é que houve uma aplicação do conhecimento da situação de contexto familiar para a de contexto não familiar ou menos familiar, ou seja, o 
participante foi capaz de perceber que utilizando a mesma estratégia seria possível a resolução do problema.

Foi observado procedimento semelhante na resolução deste pedreiro de um problema do contexto de agricultura que possuía a mesma estrutura dos anteriormente apresentados.
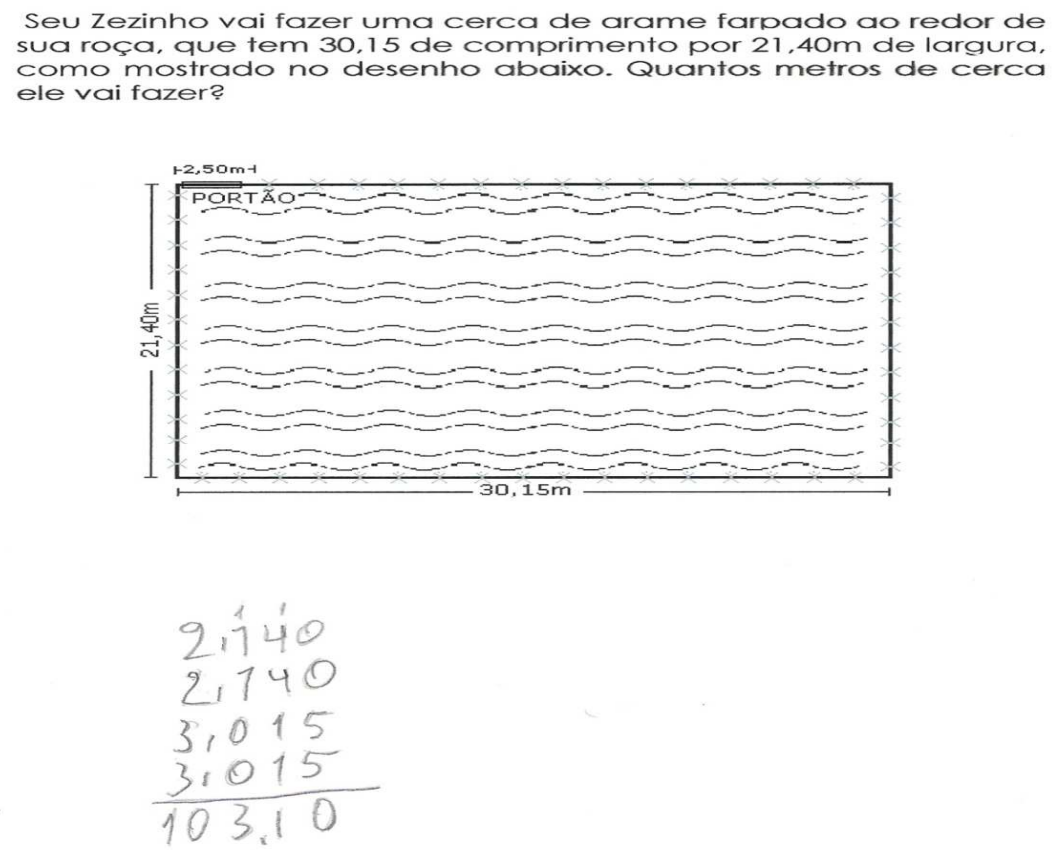

Estudante: Vou somar logo, né (sic)? Como os outros (...). É número alto.

O estudante armou a conta.

Estudante: Eu vou somar tudo isso aqui (referindo-se às medidas). Vinte e um, já botei e agora os lá de cima... zero, zero, cinco e cinco, dez: Zero, a um. Cinco, nove, dez, onze. Um e um. Um, dois, um, três. Não sobe nada. Dois, quatro, sete e três, dę: Aqui eu boto tudo. Agora en dizer... dez metros e trinta e dez centímetros. 
Pesquisadora: Por favor, leia de novo!

E: Cento e ... três metros e dez centímetros menos dois metros e cinquenta do portão.

No caso se fosse cento e três metros, descontando dois e cinquenta, ficava cem metros e

cinquenta, mas tem o dez centímetros...

P: Então vai ficar quanto?

E: Cem metros e sessenta.

P: Então, quantos metros de cerca ele vai fazer?

E: Cem metros e sessenta centímetros.

Observamos claramente que o estudante aplicou a mesma estratégia de resolução nesta situação de contexto de agricultura, contexto que podemos considerar sem nenhuma relação direta com o seu trabalho e, por isso, não ou menos familiar ao participante.

Em relação à operacionalização da adição, o que nos chama a atenção é que mesmo estando no inicio de sua escolarização, o participante optou na resolução dos três problemas pelo uso do algoritmo da adição convencional, ensinado na escola, e o realizou em todos os problemas com sucesso, demonstrando domínio na operacionalização do mesmo e que, possivelmente, esse algoritmo seja socializado em outros contextos, e não apenas no contexto escolar.

Em relação à subtração, o participante empregou mais uma vez a mesma estratégia: subtraiu dois metros e cinquenta centímetros dos cento e três metros e à diferença encontrada adicionou dez centímetros, chegando ao resultado de cem metros e sessenta centímetros de cerca a ser construída.

Esta sequência de problemas evidencia, claramente, a possibilidade de estudantes de determinada profissão transferirem seus conhecimentos para situações presentes em outras atividades profissionais. O conhecimento de área, perímetro e decimais dos estudantes não ficou, portanto, restrito aos contextos de suas profissões, mas foi utilizado em outros contextos pouco ou não familiares.

Os resultados desta pesquisa nos levam a inferir a possibilidade de que a aplicação do conhecimento da prática profissional dos estudantes da EJA em 
relação aos conceitos matemáticos pode ultrapassar o seu contexto de origem e ser aplicado em outros contextos, no momento que se evidenciou que os conhecimentos extraescolares não são limitados apenas às experiências dos estudantes, mas que os invariantes de uma situação podem ser reconhecidos em outras menos familiares.

Embora, os participantes tenham realizado com êxito grande percentual das operações com números decimais na resolução dos problemas propostos, como apresentado na Tabela 1 e nos Gráficos 1 e 2, verificamos alguns erros na realização de determinadas operações, multiplicação e subtração, que nos chamaram atenção, e por isso nos propusemos analisá-los. Como já afirmamos anteriormente, os erros devem ser vistos por nós, educadores, como indicativos do conhecimento atual do educando, e não de sua falta de conhecimento ou desinteresse. A nosso ver, cabe ao professor compreender a razão destes erros e mediar a superação dos mesmos por seus educandos. No tópico a seguir apresentamos alguns exemplos de erros tanto e cálculo relacional, como de numérico.

\section{Erros relacionais e numéricos mais comuns nas resoluções}

Neste tópico, apresentamos as categorias em relação aos erros no cálculo relacional, exemplificando duas estratégias incorretas e, em seguida, as categorias em relação aos erros no cálculo numérico, descrevendo dois erros cometidos nas resoluções dos problemas propostos.

Não ocorreram erros de cálculo relacional nos problemas envolvendo números decimais relacionados ao conceito de perímetro, por isso os exemplos que serão apresentados são de problemas envolvendo o conceito de área.

\section{Erros de cálculo relacional}

Para a análise dos erros de cálculo relacional, estes foram organizados em três categorias: (1) Utilização de procedimento aditivo, ao invés de multiplicativo, para o cálculo de área, (2) Ampliação das medidas lineares pelo número de superfícies, (3) Duplicação da medida da largura para o cálculo da área do retângulo. Em cada categoria, foram descritas as estratégias utilizadas pelos participantes na resolução dos problemas. $\mathrm{Na}$ sequencia, apresentamos duas dessas estratégias relacionadas à categoria 1 e 2, respectivamente.

O cálculo relacional, abaixo descrito, foi realizado por um participante 
(grupo dos marceneiros) ao resolver o problema no qual é solicitado o cálculo de metros quadrados de cinco terrenos para o plantio de milho. A estratégia elaborada por ele foi a multiplicação da medida do comprimento pela quantidade de superfícies, depois a multiplicação da medida da largura pela quantidade de superfícies, seguido da multiplicação dos produtos obtidos para o cálculo da área. Esta mesma estratégia foi aplicada pelo participante em outros dois problemas

Um marceneiro foi contratado para revestir alguns quadros do

Colégio Brasil. Com as seguintes medidas:

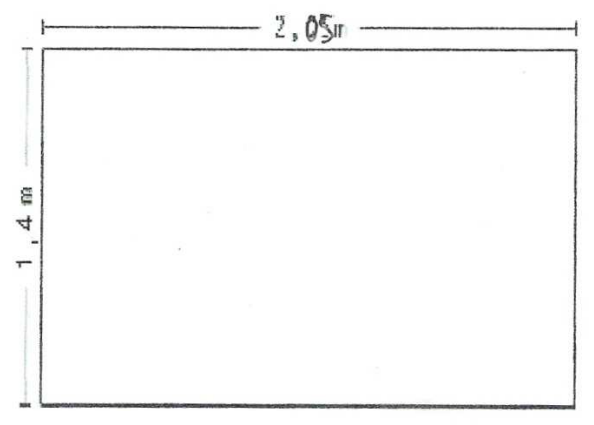

Quantos metros quadrados de fórmica serão necessários para revestir 8 quadros?

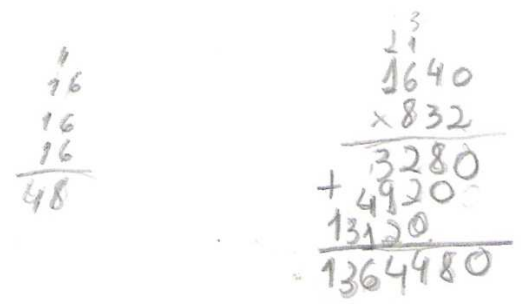

Estudante : Um metro e quatro centimetros. Deixa eu ver... (pausa) 
Pesquisador: Você está calculando?

E: É.

P: Como você está pensando?

E: Pensei aqui, né (sic)? Na largura num (sic) é dois? Ai, eu ponho os outros dois. Dois, mais dois, mais dois dá seis. Dá dezesseis. São oito? Com mais cinco centímetros. Dezesseis metros com mais cinco centímetros dá... cinco, dez, quinze, vinte.. mais vinte, dezesseis metros e quarenta centímetros, de largura

P: Sim

E: Altura, agora. A altura dá... oito alturas. Contei primeiro os metros. Deu oito, com os centímetros, se fosse cinco dá vinte. Oito metros e vinte e quatro centímetros! Oito metros e vinte oito e trinta e dois centímetros.

P: Quanto?

E: Oito metros e trinta e dois centimetros, de altura.

P: Queremos saber quantos metros quadrados de fórmica para revestir oito quadros.

(O aluno arma a conta)

E: Dois vez (sic) zero, zero. Dois vez. (sic) quatro, oito. Dois vez (sic) seis doze, vai um, aqui. Dois vez. (sic) um, dois, com um, três. Três vez. (sic) żero, três vez. (sic) quatro, doze. Três vez (sic) seis, dezoito com um dezenove. Três vez. (sic) um três, com um quatro. Zero. Quatro vez. (sic) oito dá... dezesseis com dezesseis, trinta e dois. Oito vez. (sic) seis.. seis... quarenta e oito com três, cinquenta e um. Oito vez. um, oito com cinco, dá treze. Desce o zero, oito. Dois e dois, quatro. Nove, dez, onze, quatorze. Vai um. Quatro mais um cinco e um seis. Desce o treze.

P: Quantos metros quadrados serão necessários para revestir oito quadros?

E: Treze metros e sessenta e quatro centímetros.

Zetetiké - FE/Unicamp - v. 22, n. 42 - jul/dez-2014 
Observamos que o participante inicia sua estratégia multiplicando cada medida (da largura e da altura) por oito. Ele realiza os seguintes cálculos: soma da parte inteira (da largura e da altura) de acordo com a quantidade de quadros e soma da parte decimal, também, de acordo com a quantidade de quadros, chegando aos resultados de dezesseis metros e quarenta centímetros de largura e oito metros e trinta e dois centímetros de altura. Observamos que o participante realizou o cálculo numérico de oito vezes um vírgula quatro de forma incorreta, porém analisaremos o erro de cálculo numérico mais à frente.

Dando continuidade à resolução, ele realiza o cálculo da área total dos oito quadros e chega ao resultado de treze metros e sessenta e quatro centímetros.

Ao utilizar esta estratégia, o participante obteve uma área oito vezes maior, como apresentada na figura a seguir, do que a solicitada no problema, demonstrando que interpretou incorretamente que o cálculo de oito quadros pode ser obtido multiplicando-se por oito cada uma das medidas lineares. A área a ser corretamente obtida corresponde à parte em vermelho da Figura 1 e a parte excedente encontra-se em azul.

Figura 1 - Representação da estratégia realizada participante na resolução do problema

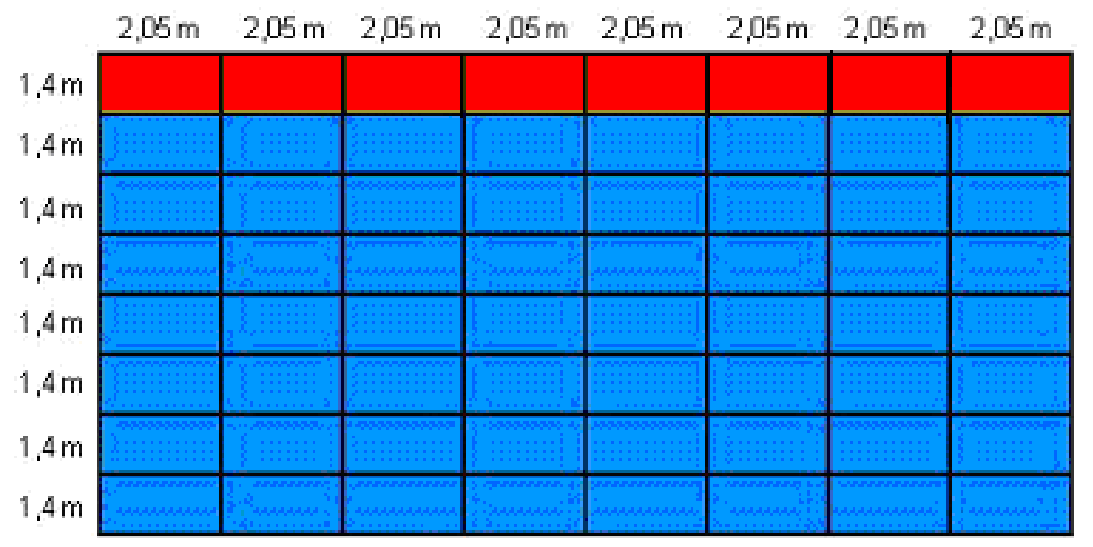

Diante de uma resolução como esta, caberia uma intervenção na qual se pudesse refletir sobre como a ampliação de dimensões lineares em $n$ unidades acrescem a área total em $n \times n$ vezes e não apenas em $n$ vezes. Seria necessário, 
assim, trabalhar outras situações que levassem a confrontações dessas distintas interpretações.

Apresentamos, a seguir, o exemplo da estratégia realizada pelo mesmo participante ao solucionar o problema no qual foi solicitado o cálculo de metros quadrados de folheado necessários para revestir as portas e gavetas de um guarda-roupa. Para tal, foi elaborada a seguinte estratégia: adição das medidas das larguras e adição das medidas dos comprimentos, seguido da multiplicação da medida da largura por dois e multiplicação dos resultados da largura e do comprimento para o cálculo da área, que também foi aplicada aos outros problemas de contextos pouco ou não familiares. 


\begin{abstract}
Um marceneiro foi contratado para revestir as portas e gavetas de um guarda-roupa com folheado de cerejeira, conforme o desenho abaixo. Quantos metros quadrados de folheado serão usados?
\end{abstract}

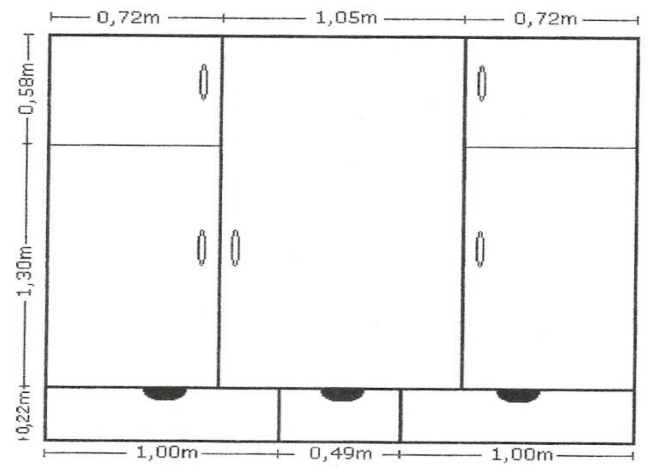

$$
\begin{aligned}
& \begin{array}{l}
0.721 \\
0.72 \\
1.05
\end{array} \\
& 1,05 \\
& \frac{105}{249}
\end{aligned}
$$
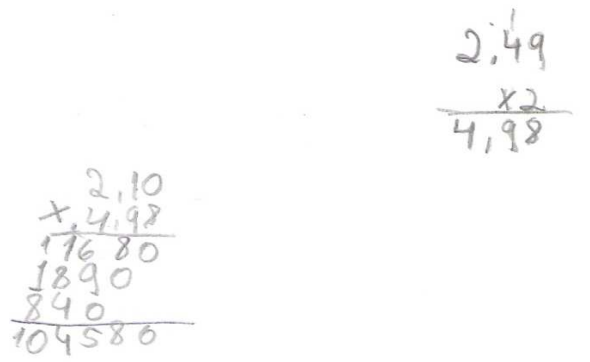

Iniciando a estratégia, o participante calculou a medida total da largura e da altura do guarda-roupa, adicionando as medidas.

Estudante: Esse tá (sic) mais complicado um pouquinho!

Pesquisadora: Você está calculando o quê?

E: A largura das portas, depois as larguras das gavetas.

O aluno arma a conta: 0,72+072+1,05 


\section{E: Deu dois metros e quarenta e nove.}

O aluno arma a conta: $0,22+1,30+0,58$

E: Aqui no caso é a largura... é o tamanho das portas e das gavetas. Dois metros e dez: Aqui é a largura (o aluno escreve " $L$ " ao lado da operação), aqui a altura (o aluno escreve "A" ao lado da operação). Dois metros e quarenta e nove centímetros

Antes de realizar o cálculo da área a ser revestida no guarda-roupa, o participante multiplica a medida da largura por dois, alegando que são duas larguras, de acordo com a fala destacada abaixo.

Estudante: Vou multiplicar a largura das gavetas e a largura das portas. Dois metros e quarenta e nove (o aluno arma a conta 2,49 X 2 ). Quatro metros e noventa e oito, é as larguras (sic) dele.

Pesquisadora: Por que você multiplicon?

E: Porque...é (sic) as larguras das gavetas e das portas. Como é a mesma, eu multipliquei pra ficar um número só pra fazer a conta.

Concluindo a estratégia, o participante realizou a multiplicação de dois vírgula dez por quatro virgula noventa e oito $(2,10 X 4,98)$ e chegou ao resultado que serão necessários dez metros e quarenta e cinco centimetros e oitenta milimetros de folheado para revestir as portas e gavetas do guarda-roupa.

Ao realizar esta estratégia, o participante apresentou dificuldade de compreensão em relação a uma característica básica do retângulo, que consiste em ter os lados opostos congruentes. Dessa forma, bastaria calcular a largura e calcular a altura e multiplicá-las para obter a área a ser revestida. O que pode ter confundido o participante foi o fato de ter duas indicações de medidas da largura, o que o levou a multiplicar a largura por dois. Salienta-se que os cálculos numéricos foram todos realizados corretamente, inclusive a multiplicação de decimal por decimal, bem como a leitura do valor final foi corretamente 
efetuada. A dificuldade apresentada refere-se à falta de clareza quanto ao cálculo necessário para obtenção da área, cabendo intervenções que possam oportunizar reflexões sobre esse conceito.

\section{Erros de cálculo numérico}

Em relação ao cálculo numérico da multiplicação, identificamos os seguintes erros: (1) não consideração da ordem dos resultados das multiplicações; (2) não consideração das ordens das parcelas obtidas na multiplicação; (3) desconsideração da parte decimal do multiplicador na operação; (4) desconsideração da reserva na soma das parcelas da multiplicação.

Apresentamos, em seguida, um exemplo no qual um participante (do grupo dos pedreiros) ao realizar o cálculo numérico da multiplicação, considerou apenas a parte inteira do multiplicador.

Ao iniciar a estratégia de resolução do problema, o participante adicionou as medidas das larguras e as medidas do comprimento do guarda-roupa. Em seguida, realizou a multiplicação dos totais obtidos $(2,49 \mathrm{~m} \times 2,10 \mathrm{~m})$ para o cálculo da área a ser revestida do guarda-roupa.

Estudante: Duas vez. (sic) dois é quatro, quatro vez quatro, né (sic)? Não, duas vez.

(sic) quatro é oito. Duas vez. (sic) quatro, oito. Duas vez. (sic) nove... Duas vez. nove, dezoito. Dezoito, eu boto tudo, né (sic)?

Pesquisadora: Você que sabe.

E: Essa conta ai eu tô (sic) apanhando dela. Não sou acostumado com esse negócio. É outra profissão, né (sic)?

P: Sim. Quantos metros de folbeado serão necessários para revestir o guarda-roupa?

E: É...é quatro metros e oitenta e um centímetro. No meu cálculo, uma média de cinco metros.

P: Cinco metros por quê?

E: Porque o espaçozinho dele é grande! Eu ia pedir cinco metros pra forrar ele. 


\begin{abstract}
Um marceneiro foi contratado para revestir as portas e gavetas de um guarda-roupa com folheado de cerejeira, conforme o desenho abaixo. Quantos metros quadrados de folheado serão usados?
\end{abstract}
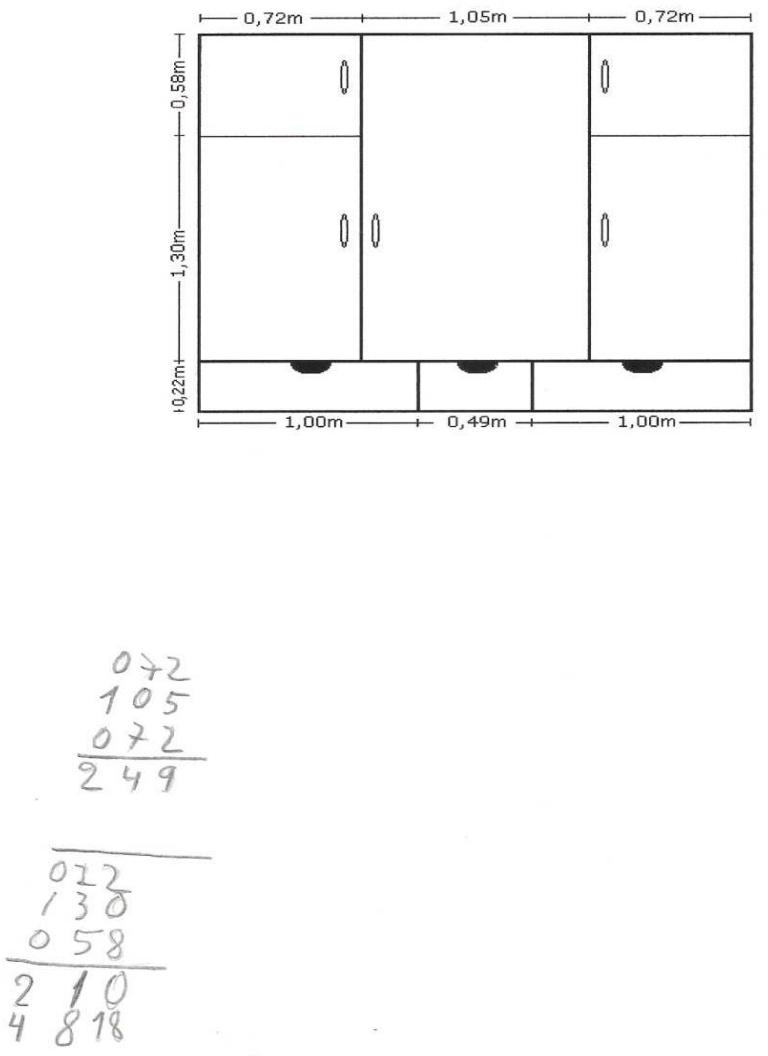

Destaca-se que, além de desconsiderar a parte decimal do multiplicador, o participante efetuou o produto incorretamente, pois 2,49 por 2 resulta em 4,98 e não 4,81 como apontado pelo aluno. O erro, porém, não se afasta em muito da ordem de grandeza da resposta correta da questão.

Observa-se, apesar do erro cometido, que parece haver influência da prática profissional na resolução apresentada por este pedreiro. Embora o 
problema seja de um contexto pouco ou não familiar ao participante, como ele mesmo destaca em sua fala, o pedreiro realizou as contas como possivelmente o faz em sua prática: arredondando os valores. Ao invés de multiplicar 2,49 por 2,10 , efetua a operação apenas por 2 , mas procura arredondar para mais no resultado, compensando os 0,10 desconsiderados na conta. É também uma prática comum arredondar para mais para não se correr o risco de se ter material de menos. O preferível na prática é arredondar para mais, mesmo que sobre um pouco de material. Este procedimento, embora incorreto do ponto de vista matemático, é uma prática comum e que não acarreta em erro no exercício prático de algumas profissões.

Seria, nesse caso, necessário refletir sobre situações nas quais cálculos precisos se fazem necessários e aquelas nas quais arredondamentos são suficientes e como proceder para realizar cálculos exatos.

Em relação ao cálculo numérico da subtração, identificamos e analisamos os seguintes erros: (1) desconsideração da necessidade de transformar um inteiro em dez décimos e (2) consideração do número maior na realização da subtração. No exemplo que segue, um participante (do grupo dos pedreiros) realizou o algoritmo convencional da subtração ao resolver o problema proposto.

Iniciando a estratégia de resolução, o participante adicionou as medidas das larguras e dos comprimentos e obteve o resultado de $55,10 \mathrm{~m}$ e, em seguida, realizou a subtração.

Estudante: Cinquenta e cinco metros e dez centímetros de madeira, de rodapé.

Pesquisadora: Sim.

E: Ah... mas, tem porta né (sic)? Tem que descontar essa porta. De diminuir, né (sic)?

(O aluno arma a subtração). Zero. Cinco para dez, cinco, a um. Um com dois, três.

Dois, cinco.

P: Quantos metros de madeira serão usados no rodapé?

E: Do total, ai deu cinquenta e dois metros e cinquenta centímetros. 
10.3m de largura, conforme o desenho abaixo, será colocado rodapé de madeira. Quantos metros de madeira seráo usados
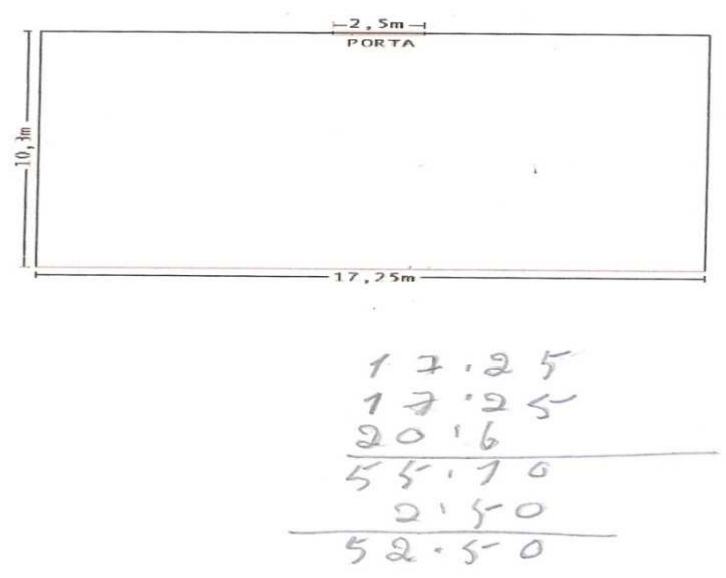

Observamos no procedimento de realização da operação, que o participante subtraiu cinco décimos de um décimo, obtendo o resultado de cinco. Ele demonstrou, neste caso, não compreender que, para efetuar esta subtração, se faz necessário a transformação de uma unidade (dos 55) em 10 décimos, para assim proceder à subtração de onze décimos menos cinco, igual a seis décimos.

Em relação ao cálculo numérico da subtração, observamos que os erros foram cometidos pelo participante ao realizar o algoritmo convencional, evidenciando a dificuldade de compreensão por parte deste em relação às regras peculiares ao algoritmo desta operação, bem como em relação às regras do Sistema de Numeração Decimal envolvidas e não apenas um descuido eventual.

Neste caso, caberia tratar situações nas quais fossem realizadas transformações de unidades de medida em seus submúltiplos e refletir sobre os casos nos quais essas conversões se fazem necessárias para realização das operações aritméticas. 


\section{Considerações finais}

Os resultados obtidos neste estudo sugerem que, ao tentar resolver situações propostas, os participantes buscaram referências na sua experiência profissional e que os conhecimentos dos pedreiros e marceneiros mostraramse significativos na formação do conceito de número decimal, devido às estratégias de cálculo utilizadas e às habilidades demonstradas pelos participantes. Os resultados sugerem, ainda, que estudantes profissionais conseguem aplicar suas estratégias de resolução para outras situações que não são comuns ao seu cotidiano.

Em relação aos erros cometidos, com maior incidência de erros numéricos que relacionais, verifica-se que os profissionais compreendiam bem as situações propostas e sentiam um pouco mais de dificuldade em operacionalizar com os decimais, do que em escolher estratégias adequadas para lidar com este campo numérico.

Embora possa haver conhecimento anterior do jovem e adulto quanto às operações com números decimais, a escola deve considerar que há dificuldades a serem superadas pelos alunos, tais como, a incompreensão dos algoritmos da subtração e multiplicação com decimais; a falta de ampla compreensão de décimos e centésimos na representação decimal; e a não associação da representação decimal com a regularidade do Sistema de Numeração Decimal.

Partindo destes resultados, queremos ressaltar que é de grande importância que os estudantes da EJA recebam um tratamento diferenciado no que diz respeito à introdução formal do conceito de número decimal na escola, uma vez que muitos deles podem demonstrar ter um conhecimento já construído e bem elaborado deste campo numérico, que precisa ser reconhecido, aproveitado em sala de aula e valorizado pela escola. O reconhecimento dos saberes dos estudantes profissionais pode conduzir à utilização dos mesmos como mediadores de conhecimentos menos desenvolvidos de outros estudantes. Estes podem interagir com colegas cujo conhecimento não seja tão desenvolvido e auxiliá-los nos seus avanços. E ainda, a aplicação de uma estratégia de resolução de situação de contexto familiar para não familiar pelo estudante abre para o professor a possibilidade de, a partir de uma situação conhecida e compreendida pelo estudante, ampliar e fazer avançar o conhecimento, ao propor outras situações de contexto desconhecido.

O estudo, assim, evidencia que a prática profissional proporciona 
aprendizagens significativas de conceitos matemáticos, mas pode não ser suficiente para um amplo domínio conceitual. Nesse sentido, a escola desempenha um importante papel de aprofundar e ampliar conhecimentos já adquiridos na prática profissional.

\section{Referências}

ABREU, Guida Maria. O uso da matemática na agricultura: o caso dos produtores de canade-açúcar. Recife: Programa de Pós-Graduação em Psicologia Cognitiva /Universidade Federal de Pernambuco, 1988. Dissertação (Mestrado em Psicologia Cognitiva).

BROUSSEAU, Guy. Les obstacles épistémologiques et les problèmes en mathématiques. Recherches en Didactique des Mathématiques. Grenoble : La Pensée Sauvage, 1983, Vol. 4. CARRAHER, Terezinha Nunes. Passando da planta para a construção: um trabalho de mestres. In: CARRAHER, Terezinha; CARRAHER, David; SCHLIEMANN Analúcia. Na vida dez, na escola zero. São Paulo: Cortez, 1988, p. 101-125.

CUNHA, Micheline; MAGINA, Sandra Maria. A medida e o número decimal: um estudo sobre a elaboração de conceito em crianças do nível fundamental. In: Encontro Nacional de Educação Matemática, 7, 2004, Recife/PE. Anais.

DANYLUK, Ocsana Sônia. Educação de Adultos: ampliando horizontes do conhecimento. Porto Alegre: Sulina, 2001.

FONSECA, Maria da Conceição. Educação Matemática de jovens e adultos: especificações, desafios e contribuições. Belo Horizonte: Autêntica, 2002.

MAGALHÃES, Verônica. A resolução de problemas de proporção e sua transferência entre diferentes conteúdos. Recife: Programa de Pós-Graduação em Psicologia Cognitiva/Universidade Federal de Pernambuco, 1990. Dissertação (Mestrado em Psicologia Cognitiva).

PORTO, Zélia. Números decimais: problemas de compreensão e representação. Recife: Universidade Federal de estou na dúvida Pernambuco, 1995. Dissertação (Mestrado em Psicologia Cognitiva).

RODRIGUES, Wanda. A aparente simplicidade da base dez. In: Seminário Internacional de Pesquisa em Educação Matemática, 2, 2003, Santos/SP, Anais.

SCHLIEMANN, Analúcia. Escolarização formal versus experiência prática na resolução de problemas. In CARRAHER, Terezinha; CARRAHER, David; SCHLIEMANN Analúcia . Na vida dez, na escola zero. São Paulo: Cortez, 1988, p.69-83.

SILVA, Valdenice da. Números decimais: no que os saberes de adultos diferem dos de criança? Recife: Universidade Federal de Pernambuco, 2006. Dissertação (Mestrado em Educação) VERGNAUD, Gerárd. Psicologia do desenvolvimento cognitivo e didáctica das matemáticas. Um exemplo: as estruturas aditivas. Análise Psicológica, v.1, p.75-90, 1986.

VYGOTSKY, Lev. A formação social da mente: o desenvolvimento dos processos psicológicos superiores. São Paulo: Martins Fontes, 1998,

Submetido em 14/08/2012

Aprovado em 27/02/2014

Zetetiké - FE/Unicamp - v. 22, n. 42 - jul/dez-2014 